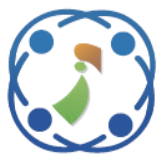

\title{
Optimal Overcurrent Relay Coordination Considering Multiple Characteristic Curve for Microgrid Protection using Hybrid PSO-MILP Technique
}

\author{
Chakit Plongkrathok $^{1} \quad$ Keerati Chayakulkheeree ${ }^{1 *}$ \\ ${ }^{I}$ School of Electrical Engineering, Suranaree University of Technology, Thailand \\ * Corresponding author's Email: keerati.ch@sut.ac.th
}

\begin{abstract}
This paper proposes an approach for the optimal setting parameters of overcurrent relay (OCR) coordination considering multiple characteristic curves. The proposed approach considers time multiplier setting (TMS) and the relay characteristic curve setting (CS) as decision variables. As an inventiveness, the CS of OCR can be chosen as decision variables, instead of fixing a single type of curve for all relays that used in many existing works. The proposed approach allows three different curve types of IEC standard characteristic curves for combination results in the optimal protection coordination, including the standard inverse (SI) curve, very inverse (VI) curve, and extremely inverse (EI) curve. The proposed technique for solving this problem is hybrid particle swarm mixed integer linear programming (PSO-MILP). To show the effectiveness of the proposed approach, several tests were carried out using the standard IEC benchmark microgrid system. A comparison with previous existing methods illustrated that the proposed technique can absolutely decrease the total operating time of the OCR by around 34 percent for OM1, around 44 percent for OM2, and slightly decrease the total CTI of the test system. Therefore, the proposed approach is outstanding in finding lower the operating times and provides suitable operation of microgrid protections under different fault allocation and operating conditions.
\end{abstract}

Keywords: Optimal overcurrent relay coordination, Microgrid protection, Artificial intelligence.

\section{Introduction}

One of the most appealing features of microgrid systems is that the power delivered to consumers who prefer an uninterruptible power resource with reliable and high quality. Furthermore, there are savings in power generation costs through the implementation of photovoltaic (PV), wind turbine (WT), distributed generator (DG), and energy storage systems (ESS) into micro-networks. Nevertheless, the penetration of DG plays a role in significantly contributing fault current into the system [1]. Therefore, the protection strategy of microgrids is a new challenge for protection engineers.

An overcurrent relays (OCR) can extensively be applied as the primary protection strategy in distribution systems, sub-transmission systems, and microgrid systems or as backup protection in transmission systems. In order to improve the fast and reliability of the protection strategy, OCRs must be operated with minimum time and able to coordinate with another relay to improve the system reliability. Consequently, the OCR can adjust the operating point by adjusting the setting parameters, including the pickup current setting $(P S)$, the time multiplier setting (TMS), and characteristic curve settings (CS). Hence, OCRs coordination can be variously formulated in optimization problems. The coordination between primary and backup relay leading highly non-linear inequality constraints to this problem.

In order to obtain better results, numerous approaches and techniques for solving the optimal setting parameter of OCR was published. In the earliest era, the $P S$ has been predetermined, and $C S$ of each relay have been set to specific characteristic curve, hence this problem has been formulated as a linear optimization. The minimum total operating time of the primary relay is the objective function 
subjected to the coordination constraint. As a result, the TMS of each relay is the output for the optimal result. The linear programming optimization [2], the dual simplex approach [3], the Big-M strategy [4], and the reverse simplex method by [5], and artificial bee colony [6] have all been proposed as solutions to these problems. Subsequently, the problem was improved to the nonlinear optimization by considering the $P S$ and the $T M S$ as a decision variable, whereas the $C S$ has remained unchanged. The objective function was minimized by avoiding the limit boundary of $T M S$ and $P S$, the coordination constraint, and the minimum operating time. In order to solve this issue, several artificial intelligence techniques were proposed. For example, adaptive modified fly fire algorithm (AMFA) was introduced in [7]. The seeker optimization (SOA), the gravitational search method (GSA), and the hybrid genetic algorithm-nonlinear programming approach (GA-NLP) were proposed in [8-10], respectively. Meanwhile, [11] developed the symbiotic organism search algorithm (SOS). Afterward, the researchers proposed that the $P S$ could be considered to be the step/discrete variable instead of the continuous variable to illustrate the realized industrial OCR. The problem was transformed into a mixed-integer nonlinear optimization problem (MINLP). Numerous techniques were proposed to solve this problem, for example, modified seeker algorithm (MSA) [12], hybrid whale optimization (HWOA) [13], ant lion optimization (ALO), and the artificial immune system (AIS) [14], hybrid GA-LP [15]. In recent years, various novel constraints were implemented for representing the practical industrial OCR such as the plug setting multiplier (PSM) constraint to be within the range of 1.1 times to 20 times [16], and the range of 1.1 times to 100 times [17]. Then, researchers have focused on the maximum PSM as a decision variable that can reduce the total operating time and total CTI of the relay [18], considering the transient stability constraint to ensure the network transient stability in [14]. In another way, the researcher demonstrated that various types of $C S$ have an impact on the relay's operating time. According to the results, the mixed $C S$ type solutions outperformed the fixed $C S$ type solution [19]. Consequently, the researcher proposed that the $C S$ and $T M S$ are decision variables by fixed one integer variable of each OCR for represented the $C S$, while the $P S$ is predefined. Then the problem became mixed-integer linear programming (MILP). The problem was solved by integer code genetic algorithm (ICGA) subjected to coordination constraint, operating time constraint, and PSM constraint. The results show that this method is the most effective in decreasing the total operating time of the relay [20].

As a result, this paper proposes an approach for optimal OCR coordination considering multiple $C S$, that consider TMS and $C S$ as decision variables. The formulation of this paper is MILP optimization. As a novelty, this paper represents a novel problem formulation by dividing $C S$ into multiple sections depending on the number of $C S$ types that are considered, instead of using a single integer variable of each OCR for representing $C S$ as in recent existing work [20]. The hybrid PSO-MILP technique was developed to solve this problem. The coordination constraint, the operating time constraint, and the PSM constraint were considered in this paper. To show the capability of the proposed technique, the result was compared with those previous papers [16-18, 20], in the same test system.

The following are the five sections of this paper. The formulation of the objective function, the determination of all variables, the limit boundary, and all of the constraints in this problem are all represented in section 2 . The procedure of proposed technique is obtained in section 3. The optimal results and discussions of the proposed technique on the IEC benchmark microgrid test system is presented in section 4 . The conclusion is contained in section 5 .

\section{Mathematical formulation}

The IEC standard OCR has inverse time-current characteristics. The operating time of OCR is depending on short circuit current flowing through relay and setting parameters include $T M S, P S$, and $C S$. In this paper, the decision variables are $T M S$ and $C S$, while $P S$ is predetermined of each OCR. The objective function $(O F)$ of this problem is to minimize the total operating time of all the OCRs present in the system. The function is to be minimized so that each relay operates in minimum time and the reliability of the system is maintained by the constraints. The mathematical formulation can be expressed as follow.

Minimize,

$$
\begin{array}{r}
O F=\sum_{k=1}^{N F} \sum_{j=1}^{N R}\left(C_{S I, j} T_{S I, j, k}+C_{V I, j} T_{V I, j, k}+\right. \\
\left.C_{E I, j} T_{E I, j, k}\right), \quad(1)
\end{array}
$$

where,

$$
T_{S I, j, k}=\frac{0.14 T M S_{j}}{\left(P S M_{j k}\right)^{0.02}-1},
$$




$$
\begin{aligned}
& T_{V I, j, k}=\frac{13.5 T M S_{j}}{\left(P S M_{j k}\right)^{1}-1} \\
& T_{E I, j, k}=\frac{80 T M S_{j}}{\left(P S M_{j k}\right)^{2}-1} \\
& P S M_{j k}=\frac{I_{j k}}{\left(P S_{j} C T R_{j}\right)}
\end{aligned}
$$

Subjected to the standard curve selection constraint,

$$
\begin{aligned}
& C_{S I, j}, C_{V I, j}, C_{E I, j} \in\{0,1\}, j=1, \ldots, N R, \\
& C_{S I, j}=\left\{\begin{array}{c}
0, \text { if the relay is not SI curve } \\
1, \text { if the relay is SI curve }
\end{array},\right. \\
& C_{V I, j}=\left\{\begin{array}{c}
0, \text { if the relay is not VI curve } \\
1, \text { if the relay is VI curve }
\end{array},\right. \\
& C_{E I, j}=\left\{\begin{array}{c}
0, \text { if the relay is not EI curve } \\
1, \text { if the relay is EI curve }
\end{array},\right. \\
& C_{S I, j}+C_{V I, j}+C_{E I, j}=1, j=1, \ldots, N R,
\end{aligned}
$$

the time multiplier limit boundary,

$$
T M S_{j}^{\min } \leq T M S_{j} \leq T M S_{j}^{\max }, j=1, \ldots, N R,
$$

the plug setting multiplier constraint,

$$
P S M_{j}^{\min } \leq P S M_{j} \leq P S M_{j}^{\max }, j=1, \ldots, N R
$$

the coordination constraint,

$$
T_{b, k}-T_{p, k} \geq C T I, k=1, \ldots, N F
$$

the operating time constraint,

$$
T_{j, k}^{\max } \geq T_{j, k} \geq T_{j, k}^{\min }, j=1, \ldots, N R .
$$

Where,

\footnotetext{
$T_{S I, j, k} \quad$ is the operating time of relay $j$ with standard inverse curve type when the fault occurs at point $k$,

$T_{V I, j, k} \quad$ is the operating time of relay $j$ with very inverse curve type when the fault occurs at point $k$,
}

$T_{E I, j, k}$ is the operating time of relay $j$ with extremely inverse curve type when the fault occurs at point $k$,

$T M S_{j} \quad$ is the time multiplier setting of relays $j$,

$T M S_{j}^{\text {max }}$ is the maximum time multiplier of relay $j$,

$T M S_{j}^{\text {min }}$ is the minimum time multiplier of relay $j$,

$P S M_{j} \quad$ is the plug setting multiplier of relay $j$,

$P S M_{j}^{\max }$ is the maximum plug setting multiplier of relay $j$,

$P S M_{j}^{\text {min }}$ is the minimum plug setting multiplier of relay $j$,

$T_{b, k} \quad$ is the operation time of the backup relay $b$ when fault $k$ occurs,

$T_{p, k} \quad$ is the operation time of the primary relay $p$, for the same fault,

CTI is the coordination time interval,

$T_{j, k}^{\min }$ is the minimum operating of each relay $j$ when fault $k$ occurs,

$T_{j, k}^{\max }$ is the maximum operating of each relay $j$ when fault $k$ occurs.

$I_{j k} \quad$ is the short-circuit current flowing through relay $j$ when fault at $k$ is occurred (A),

$P S_{j} \quad$ is the pickup setting of relay $j(\mathrm{~A})$,

$C T R_{j} \quad$ is the CT ratio of relay $j$,

$N F \quad$ is a number of faults that can be take place in the system,

$N R$ is a number of the operating relays when fault occur at point $k$.

By Eqs. (6-10), the OCR standard CS of each relay can be chosen only one from SI, VI, or EI.

\section{PSO-MILP technique}

The TMS of each OCR is a continuous variable while the $C S_{I}, C_{V I}$, and $C_{E I}$ are a binary integer variable. Thus, the mathematical formulation of this problem is adapted to the mixed-integer nonlinear optimization. Meanwhile, traditional particle swarm optimization (PSO) can only solve problems with continuous variables [21]. Hence, the PSO-MILP technique is implemented to solve this problem. The proposed method including two computational phases consist of a main loop and subroutines. A main loop is used the PSO technique to find the optimal TMS of each OCR. A subroutine is used the MILP technique to obtain the optimal $C S_{I}, C_{V I}$, and $C_{E I}$. The proposed technique computation of each population is shown step by step as bellow.

Step 1: Random initial position of the population matrix $\left(\mathbf{X}_{\text {TMS }}\right)$ within the TMS limited boundary in Eq. (11),

$$
\boldsymbol{X}_{T M S}=\left[T M S_{i}, \ldots, T M S_{N R}\right]
$$




$$
\begin{aligned}
T M S_{i} & =\operatorname{rand}\left(T M S_{i}^{\min }, T M S_{i}^{\max }\right), i \\
& =1, \ldots, N R
\end{aligned}
$$

Step 2: Calculate $T_{S I, j, k}, T_{V I, j, k}$, and $T_{E I, j, k}$ value in Eq. (1) by substitute $\mathbf{X}_{\text {TMS }}$ from Eq. (16) to Eqs. (2-5). Then, the $O F_{\text {new }}$ will be integer programming optimization with binary integer decision variables $\left(C S_{I}, C_{V I}\right.$, and $\left.C_{E I}\right)$ of each OCR.

$$
O F_{\text {new }}=O F_{\text {old }}(\text { subtitute } T M S \text { in Eq.(1-5)) }
$$

Step 3: Solve MILP with objective function form Eq. (17) subjected to constraints in Eqs. (6-10), and Eqs. (12-14) to obtain optimal $C S_{I}, C_{V I}$, and $C_{E I}$ of each population matrix.

Minimize the objective function in: Eq. (17)

Subjected to: Eq. (6-10), and Eqs. (12-14)

Obtain: $\boldsymbol{X}_{C S}=\left[\begin{array}{c}C_{S I, i}, \ldots, C_{S I, N R} \\ C_{V I, i}, \ldots, C_{V I, N R} \\ C_{E I, i}, \ldots, C_{E I, N R}\end{array}\right], i=1, \ldots, N R$

Step 4: Find the pbest and gbest of each population matrix form Eqs. $(17,18)$.

Step 5: Update velocity and position of each population matrix from Eq. (16) by Eqs. (19-22).

$$
\begin{aligned}
& \boldsymbol{V}^{\boldsymbol{k}+\mathbf{1}}=w \boldsymbol{V}^{\boldsymbol{k}}+A_{1}+A_{2}, \\
& A_{1}=c_{1} r_{1}\left(\text { pbest }_{i}^{k}-\boldsymbol{X}^{\boldsymbol{k}}\right), \\
& A_{2}=c_{2} r_{2}\left(\text { gbest }^{k}-\boldsymbol{X}^{\boldsymbol{k}}\right), \\
& \boldsymbol{V}_{\boldsymbol{i}}^{\boldsymbol{k}}=\left[V_{1}^{k}, \ldots, V_{3 N R}^{k}\right], \\
& \boldsymbol{X}_{\boldsymbol{i}}^{\boldsymbol{k}+\mathbf{1}}=\boldsymbol{X}^{\boldsymbol{k}}+\boldsymbol{V}^{\boldsymbol{k}+\mathbf{1}}, \\
& \boldsymbol{X}_{T M S}^{\mathrm{new}}=\boldsymbol{X}_{\boldsymbol{i}}^{\boldsymbol{k}+\mathbf{1}},
\end{aligned}
$$

where, $k$ indicates the iteration, $w$ is the inertia weight, $v_{k}^{i}$ is the $i$ particle's velocity vector, $x_{k}^{i}$ is the $i$ particle's vector, gbest $^{k}$ is the historically best position of the entire swarm, pbest ${ }_{i}^{k}$ is the historically best position of particle $i, c_{1}$ and $c_{2}$ are the personal and global learning coefficients, respectively, while $r_{1}$ and $r_{2}$ are uniformly distributed random numbers in the range $[0,1]$.

Step 6: Repeat step 2-5 until the maximum iteration.

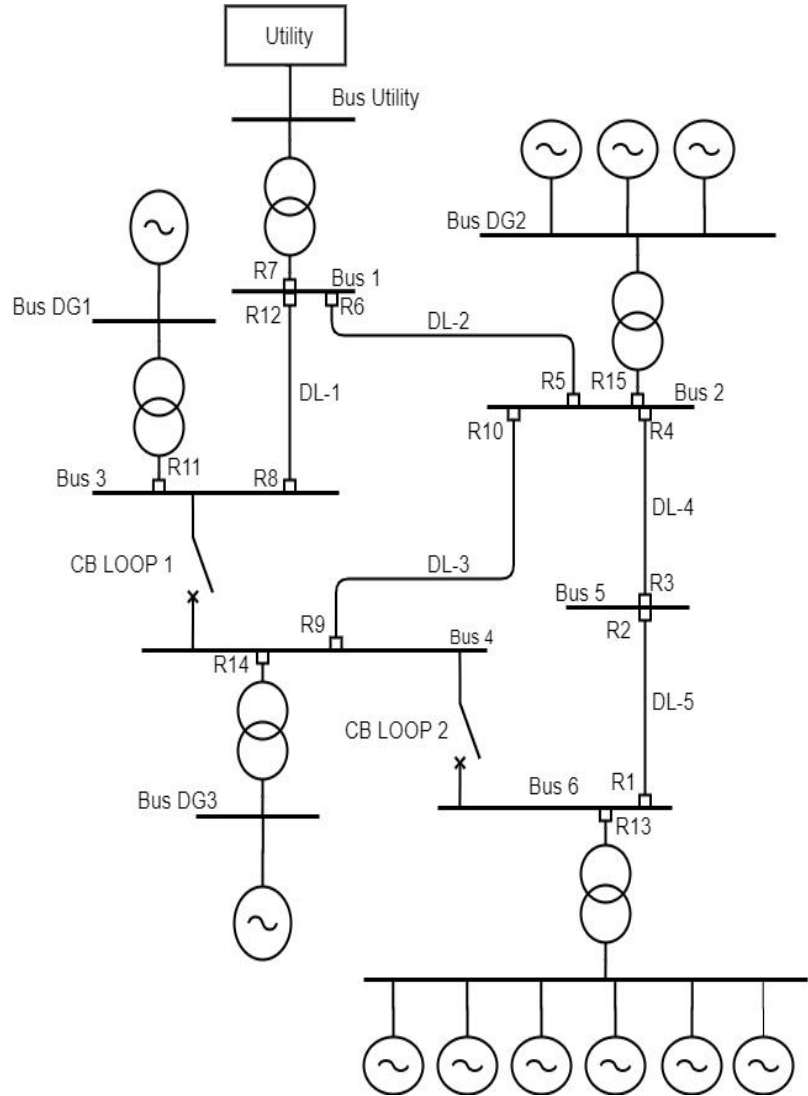

Figure. 1 an IEC benchmark micro-grid test system [20]

Table 1. The circuit breaker status of each OM

\begin{tabular}{l|l|l|l|l|l}
\hline OM & Utility & DG1 & DG2 & DG3 & DG4 \\
\hline OM1 & on & off & off & off & off \\
\hline OM2 & on & on & on & on & on \\
\hline
\end{tabular}

\section{Results and discussions}

\subsection{Test case}

The proposed approach was investigated on the IEC benchmark microgrid test system [16-18, 20] with various operating modes (OMs) as shown in Fig. 1. In this system, the OM can be classified into two conditions (OM1 and OM2) depend on the circuit breaker status as show in Table 1. The IEC benchmark microgrid consist of main six buses, six constant power loads, two distributed synchronous generators (DG1 and DG3), two wind turbines generator (DG-2 and DG-4), and five distribution lines (DL-1, DL-2, ..., DL-5). The three-phase faults occur in the middle point of each distribution line (F1-F5).

Therefore, F1 denote the fault on distribution line DL-5. F2, F3, and F4 represents the fault on distribution lines DL-4, DL-2, and DL-1, respectively. F5 indicates the fault on lines DL-3. The fault level on each distribution line within various OMs can be seen in Fig. 2. To address these 
faults that can be occurred in this system, the relay was established at every end of the distribution line and the common coupling point of each DG (R1R15). The parameters and fault levels of the system are referred to [22-23]. To avoid the complexity of the system, CB LOOP 1 and CB LOOP 2 are considered in open circuit status on any $\mathrm{OM}$.

\subsection{Simulation setup}

The limit boundary of decision variables and the constant parameters of every constraint utilized are the same as in [20] for compare the optimal solutions. Therefore, the $T M S_{j}$ limit was set between $T M S_{j}^{\text {min }}$ and $T M S_{j}^{\text {max }}$, with $T M S_{j}^{\text {min }}$ at 0.05 and $T M S_{j}^{\text {max }}$ at 15. Table 2 shows the CT ratio and $P S$ of each OCR. $P S M_{j}$ has a range of $1.1 P S M$ to 100 $P S M$ as its limit. $T_{j, k}$ has a range of 0.01 to 2 seconds, and the CTI utilized is 0.3 seconds. As a result, a variety of optimal solutions are accessible. Five hundred swarm sizes are used to find the closest global optimum solution. To reduce variation, the 30 trials test is used. In this paper $c_{1}$ and $c_{2}$ are 1.49.

\subsection{Simulation results}

\subsubsection{OM1 results}

In OM1, the test system which is connected to the utility, but all of DG is not energized. As a result, the power flow and the short circuit flow are in the same direction. Current flows from the utility to the load point or fault location. As a result, under this operational mode, just six relays are desired to detect (R2, R4, R6, R7, R10, R12). Table 3 demonstrates the coordination schemes and short circuit current passing through each OCR in this operating mode. Table 4 provides the optimal results of the proposed approach for each OCR. Table 5 shows the operating time of each relay when a fault occurs.

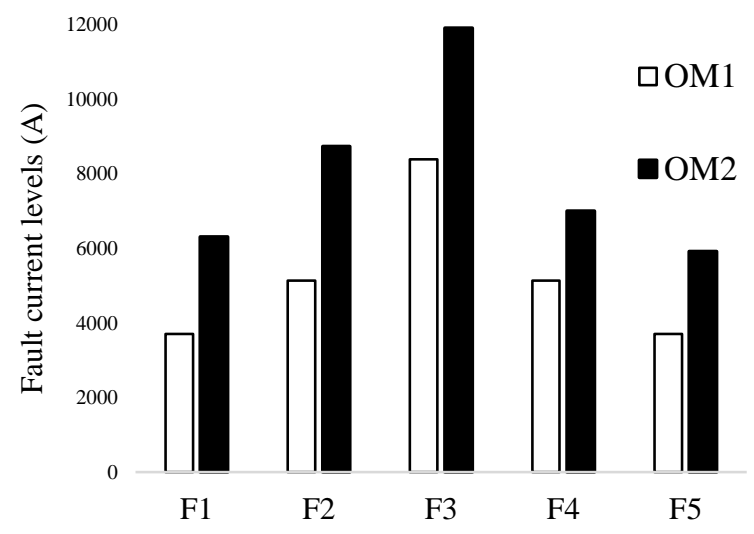

Figure. 2 Fault current level of both OM [21]
Table 2. The CT ratio and $P S$ of each OCR

\begin{tabular}{l|l|l|l|l|l}
\hline Relay & $\begin{array}{l}\text { CT } \\
\text { ratio }\end{array}$ & $\boldsymbol{P S}$ & Relay & $\begin{array}{l}\text { CT } \\
\text { ratio }\end{array}$ & $\boldsymbol{P S}$ \\
\hline R1 & 400 & 0.50 & R9 & 400 & 0.50 \\
\hline R2 & 400 & 0.50 & R10 & 400 & 0.50 \\
\hline R3 & 400 & 0.50 & R11 & 400 & 0.65 \\
\hline R4 & 400 & 0.50 & R12 & 400 & 0.50 \\
\hline R5 & 400 & 0.50 & R13 & 400 & 0.88 \\
\hline R6 & 400 & 0.50 & R14 & 400 & 0.65 \\
\hline R7 & 1200 & 1.00 & R15 & 400 & 0.65 \\
\hline R8 & 400 & 0.50 & & & \\
\hline
\end{tabular}

Table 3. The coordination schemes of OM1 [16]

\begin{tabular}{|c|c|c|c|c|c|}
\hline $\begin{array}{l}\text { Fault } \\
\text { Point }\end{array}$ & RP1 & RB1.1 & RB1.2 & RP2 & RB2.1 \\
\hline $\mathrm{F} 1$ & $\begin{array}{l}\text { R2 } \\
3695\end{array}$ & $\begin{array}{l}\text { R4 } \\
3695\end{array}$ & - & $\begin{array}{l}\text { R1 } \\
-\end{array}$ & $\begin{array}{l}\text { R13 } \\
-\end{array}$ \\
\hline $\mathrm{F} 2$ & $\begin{array}{l}\mathrm{R} 4 \\
5130 \\
\end{array}$ & $\begin{array}{l}\text { R6 } \\
5130\end{array}$ & $\begin{array}{l}\text { R15 } \\
-\end{array}$ & $\begin{array}{l}\text { R3 } \\
-\end{array}$ & $\begin{array}{l}\text { R1 } \\
-\end{array}$ \\
\hline F3 & $\begin{array}{l}\text { R6 } \\
8375\end{array}$ & $\begin{array}{l}\text { R7 } \\
8375\end{array}$ & $\begin{array}{l}\text { R8 } \\
-\end{array}$ & $\begin{array}{l}\text { R5 } \\
-\end{array}$ & $\begin{array}{l}\text { R15 } \\
-\end{array}$ \\
\hline $\mathrm{F} 4$ & $\begin{array}{l}\text { R12 } \\
5130\end{array}$ & $\begin{array}{l}\text { R7 } \\
5130\end{array}$ & $\begin{array}{l}\text { R5 } \\
-\end{array}$ & $\begin{array}{l}\text { R8 } \\
-\end{array}$ & $\begin{array}{l}\text { R11 } \\
-\end{array}$ \\
\hline F5 & $\begin{array}{l}\text { R10 } \\
3695\end{array}$ & $\begin{array}{l}\text { R6 } \\
3695\end{array}$ & $\begin{array}{l}\text { R15 } \\
-\end{array}$ & $\begin{array}{l}\text { R9 } \\
-\end{array}$ & $\begin{array}{l}\text { R14 } \\
-\end{array}$ \\
\hline
\end{tabular}

Table 4. The optimal results for OM1

\begin{tabular}{l|l|l|l|l|l}
\hline \multirow{2}{*}{ Relay } & \multicolumn{5}{|c}{ Proposed Approach } \\
\cline { 2 - 6 } & $T M S$ & $C S_{I}$ & $C_{V I}$ & $C_{E I}$ & $C S$ \\
\hline R1 & - & - & - & - & - \\
\hline R2 & 0.05 & 0 & 0 & 1 & IEC-EI \\
\hline R3 & - & - & - & - & - \\
\hline R4 & 1.3262 & 0 & 0 & 1 & IEC-EI \\
\hline R5 & - & - & - & - & - \\
\hline R6 & 3.7897 & 0 & 0 & 1 & IEC-EI \\
\hline R7 & 0.1339 & 1 & 0 & 0 & IEC-SI \\
\hline R8 & - & - & - & - & - \\
\hline R9 & - & - & - & - & - \\
\hline R10 & 0.05 & 0 & 0 & 1 & IEC-EI \\
\hline R11 & - & - & - & - & - \\
\hline R12 & 0.0821 & 0 & 0 & 1 & IEC-EI \\
\hline R13 & - & - & - & - & - \\
\hline R14 & - & - & - & - & - \\
\hline R15 & - & - & - & - & - \\
\hline
\end{tabular}

Table 3. shows that the primary and backup relay can see the same magnitude fault current for a one fault source because this operating condition has a radial topology. Thus, the fault current level is increase when the fault point near the fault source and decrease when fault point far from fault source. From the optimal results in Table 4, we can observe that, with the setting of $C S$ as decision variable, the proposed method can completely decrease the minimum operating time of the system form fixed 
CS method in [7-10].

The proposed algorithm provides the results with several types of $C S$, not a single type of curve. The CSs obtained by the proposed method are mostly IEC-EI, because it provides the minimum operating time than other curves. Meanwhile, the trend of TMSs are converge to the lower bound, but they can slightly increase to avoid the constraint violation. The proposed method improves the objective function by around $34 \%$ from the previous paper [20] while the total $C T I$ of the system is slightly decrease from [20]. The coordination curve of each OCR for the proposed approach are shown in Fig. 3.

Table 5. The operating times of OCRs for OM1

\begin{tabular}{|c|c|c|c|c|c|}
\hline \multirow{2}{*}{$\begin{array}{l}\text { Fault } \\
\text { Point }\end{array}$} & \multirow{2}{*}{ Relay } & \multicolumn{2}{|c|}{ ICGA [20] } & \multicolumn{2}{|c|}{ Proposed } \\
\hline & & $T_{j, k}$ & CTI & $T_{j, k}$ & CTI \\
\hline \multirow[t]{2}{*}{ F1 } & $\mathrm{R} 2$ & 0.0118 & \multirow{2}{*}{0.30} & 0.0118 & \multirow{2}{*}{0.30} \\
\hline & R4 & 0.3118 & & 0.3118 & \\
\hline \multirow[t]{2}{*}{$\mathrm{F} 2$} & $\mathrm{R} 4$ & 0.2976 & \multirow{2}{*}{0.30} & 0.1615 & \multirow{2}{*}{0.30} \\
\hline & R6 & 0.5976 & & 0.4615 & \\
\hline \multirow[t]{2}{*}{$\mathrm{F} 3$} & R6 & 0.5976 & \multirow{2}{*}{0.34} & 0.173 & \multirow{2}{*}{0.3} \\
\hline & R7 & 0.9372 & & 0.473 & \\
\hline \multirow[t]{2}{*}{ F4 } & R12 & 0.01 & \multirow{2}{*}{1.00} & 0.01 & \multirow{2}{*}{0.6257} \\
\hline & R7 & 1.01 & & 0.6357 & \\
\hline \multirow[t]{2}{*}{ F5 } & R10 & 0.0118 & \multirow{2}{*}{0.604} & 0.0118 & \multirow{2}{*}{0.879} \\
\hline & R6 & 0.6159 & & 0.8908 & \\
\hline Total & & 4.19 & 2.544 & 3.14 & 2.405 \\
\hline
\end{tabular}

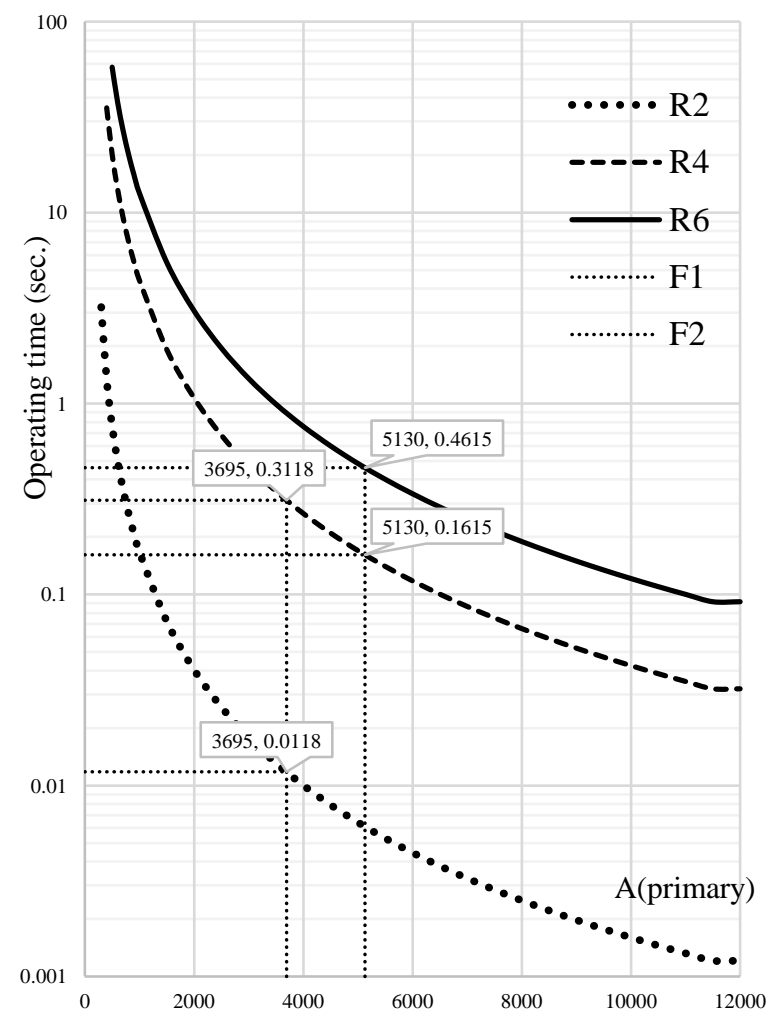

Figure. 3 The coordination curve of OCR in OM1
Table 6. The coordination schemes of OM2 [16]

\begin{tabular}{l|l|l|l|l|l}
\hline $\begin{array}{l}\text { Fault } \\
\text { Point }\end{array}$ & RP1 & RB1.1 & RB1.2 & RP2 & RB2.1 \\
\hline F1 & R2 & R4 & - & R1 & R13 \\
& 4648 & 4648 & & 1648 & 1648 \\
\hline F2 & R4 & R6 & R15 & R3 & R1 \\
& 7260 & 5443 & 920 & 1465 & 1465 \\
\hline F3 & R6 & R7 & R8 & R5 & R15 \\
& 9256 & 8375 & 923 & 2635 & 737 \\
\hline F4 & R12 & R7 & R5 & R8 & R11 \\
& 5998 & 4572 & 1439 & 991 & 991 \\
\hline F5 & R10 & R6 & R15 & R9 & R14 \\
& 4913 & 3416 & 578 & 991 & 991 \\
\hline
\end{tabular}

Table 7. The optimal results for OM2

\begin{tabular}{l|l|l|l|l|l}
\hline \multirow{2}{*}{ Relay } & \multicolumn{5}{|c}{ Proposed Approach } \\
\cline { 2 - 6 } & $T M S$ & $C S_{I}$ & $C_{V I}$ & $C_{E I}$ & $C S$ \\
\hline $\mathrm{R} 1$ & 0.2475 & 0 & 0 & 1 & IEC-EI \\
\hline $\mathrm{R} 2$ & 0.0674 & 0 & 0 & 1 & IEC-EI \\
\hline $\mathrm{R} 3$ & 0.05 & 0 & 0 & 1 & IEC-EI \\
\hline $\mathrm{R} 4$ & 2.089 & 0 & 0 & 1 & IEC-EI \\
\hline $\mathrm{R} 5$ & 0.1967 & 0 & 0 & 1 & IEC-EI \\
\hline $\mathrm{R} 6$ & 3.9472 & 0 & 0 & 1 & IEC-EI \\
\hline $\mathrm{R} 7$ & 0.1266 & 1 & 0 & 0 & IEC-SI \\
\hline $\mathrm{R} 8$ & 0.1135 & 0 & 0 & 1 & IEC-EI \\
\hline $\mathrm{R} 9$ & 0.05 & 0 & 0 & 1 & IEC-EI \\
\hline $\mathrm{R} 10$ & 0.0753 & 0 & 0 & 1 & IEC-EI \\
\hline $\mathrm{R} 11$ & 0.1428 & 0 & 1 & 0 & IEC-VI \\
\hline $\mathrm{R} 12$ & 0.1123 & 0 & 0 & 1 & IEC-EI \\
\hline $\mathrm{R} 13$ & 0.1625 & 0 & 1 & 0 & IEC-VI \\
\hline $\mathrm{R} 14$ & 0.0978 & 0 & 1 & 0 & IEC-VI \\
\hline $\mathrm{R} 15$ & 0.0885 & 1 & 0 & 0 & IEC-SI \\
\hline
\end{tabular}

\subsubsection{OM2 results}

In the OM2, the test system is connected to the utility and all of DG are energized. The power flow and the short circuit current flow can be in bidirection and complex. The direction of current flow is from utility and DGs to load point or fault point. All relays are required to protect the system under this operating condition. The coordination schemes and short circuit current flowing through each relay of this operating mode are shown in Table 6. Table 7 provides the optimal results of the proposed approach for each OCR. Table 8 shows the operating time of each relay when fault occurs

Table 6 shows that when F1 occurs, the fault flows current from DG4 is detected by relays R1 and R13. The fault current flows in a different direction from the utility and upstream DGs (DG1, DG2, DG3). Relays R2 and R4 detect these fault current flows. Similarly, to when F2 occurs, the R3 and R1 must operate together to clear this fault from DG4. Meanwhile, fault flows current from the utility and upstream DGs are necessary to operate R4, R6, and R15. As a result, when F3 occurs, R5 and R15 
will operate to clear the fault from downstream DG (DG2, DG3, DG4). For this fault from the utility and DG1, R6, R7, and R8 must be operational. As a result, when fault F4 occurs, R8 and R11 from DG1 are required to operate for this fault. R12, R7, and $\mathrm{R} 5$ are required to operate for this fault from the utility and downstream DGs. On the other hand, R9 and R14 are required to operate for this fault from DG3 when F5 occurs. In the meantime, R10, R6, and R15 must operate for this fault from a different fault source. As a consequence, when the number of fault sources increases, the coordination schemes must become more sophisticated in order to preserve system reliability.

From Table 7, the CS were provided by the proposed algorithm are mostly IEC EI, similar to OM1, the trend of TMS still converged as close as possible to lower bound. The proposed algorithm results to the best objective function value, around $44 \%$ lower than [20]. The results also shown that the proposed algorithm can effectively improve the system reliability from [20] as illustrated in Table 8. The coordination curve of each OCR for the proposed approach can be seen in Fig. 4.

\subsubsection{The summary results of the proposed technique}

With the proposed method, the total operating

Table 8. The operating times of OCRs for OM2

\begin{tabular}{|c|c|c|c|c|c|}
\hline \multirow{2}{*}{$\begin{array}{l}\text { Fault } \\
\text { Point }\end{array}$} & \multirow{2}{*}{ Relay } & \multicolumn{2}{|c|}{ ICGA [20] } & \multicolumn{2}{|c|}{ Proposed } \\
\hline & & $T_{j, k}$ & CTI & $T_{j, k}$ & CTI \\
\hline \multirow[t]{4}{*}{$\mathrm{F} 1$} & $\mathrm{R} 2$ & 0.0405 & \multirow{2}{*}{0.3} & 0.01 & \multirow{2}{*}{0.3} \\
\hline & $\mathrm{R} 4$ & 0.3405 & & 0.31 & \\
\hline & R1 & 0.2858 & \multirow{2}{*}{0.3} & 0.2959 & \multirow{2}{*}{0.3} \\
\hline & $\mathrm{R} 13$ & 0.5858 & & 0.5959 & \\
\hline \multirow[t]{5}{*}{$\mathrm{F} 2$} & $\mathrm{R} 4$ & 0.3405 & \multirow{3}{*}{0.625} & 0.1269 & \multirow{3}{*}{0.6} \\
\hline & R6 & 0.6629 & & 0.4269 & \\
\hline & $\mathrm{R} 15$ & 0.6406 & & 0.4269 & \\
\hline & R3 & 0.0302 & \multirow{2}{*}{0.3} & 0.0759 & \multirow{2}{*}{0.3} \\
\hline & $\mathrm{R} 1$ & 0.3301 & & 0.3759 & \\
\hline \multirow[t]{5}{*}{ F3 } & R6 & 0.6629 & \multirow{3}{*}{0.6} & 0.1475 & \multirow{3}{*}{0.6} \\
\hline & R7 & 0.9628 & & 0.4475 & \\
\hline & $\mathrm{R} 8$ & 0.9629 & & 0.4475 & \\
\hline & R5 & 0.186 & \multirow{2}{*}{0.553} & 0.0911 & \multirow{2}{*}{0.415} \\
\hline & $\mathrm{R} 15$ & 0.7386 & & 0.5063 & \\
\hline \multirow[t]{5}{*}{ F4 } & $\mathrm{R} 12$ & 0.0405 & \multirow{3}{*}{1.66} & 0.01 & \multirow{3}{*}{0.944} \\
\hline & R7 & 1.4 & & 0.6539 & \\
\hline & R5 & 0.3405 & & 0.301 & \\
\hline & $\mathrm{R} 8$ & 0.8467 & \multirow{2}{*}{0.3} & 0.3857 & \multirow{2}{*}{0.3} \\
\hline & R11 & 1.14 & & 0.6857 & \\
\hline \multirow[t]{5}{*}{ F5 } & $\mathrm{R} 10$ & 0.0405 & \multirow{3}{*}{1.157} & 0.01 & \multirow{3}{*}{1.701} \\
\hline & R6 & 0.3405 & & 1.0861 & \\
\hline & $\mathrm{R} 15$ & 0.8976 & & 0.6353 & \\
\hline & R9 & 0.1792 & \multirow{2}{*}{0.3} & 0.1698 & \multirow{2}{*}{0.3} \\
\hline & R14 & 0.4792 & & 0.4698 & \\
\hline Total & & 12.48 & 6.09 & 8.701 & 5.76 \\
\hline
\end{tabular}

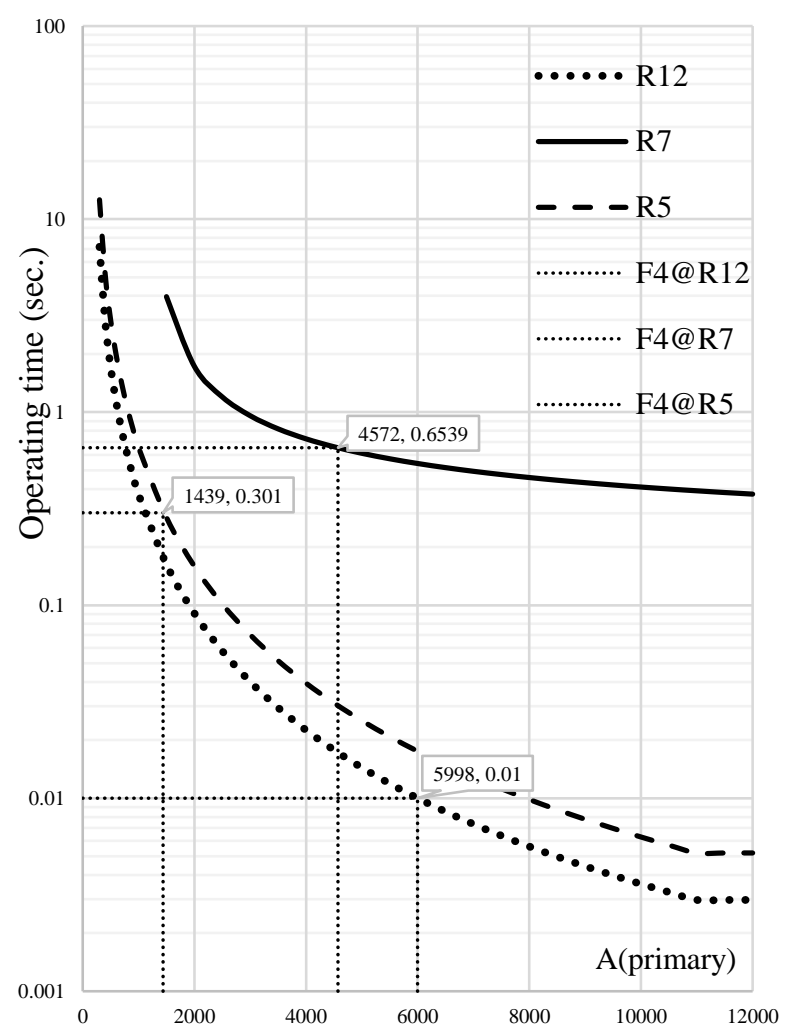

Figure. 4 The coordination curve of OCR in OM2

Table 9. A comparative study with previous works

\begin{tabular}{l|l|l|l|l|l}
\hline $\begin{array}{l}\text { Operating } \\
\text { modes }\end{array}$ & {$[\mathbf{1 6}]$} & {$[\mathbf{1 7 ]}$} & {$[\mathbf{1 8}]$} & {$[\mathbf{2 0}]$} & Proposed \\
\hline OM1 & 7.53 & 6.64 & 4.99 & 4.19 & 3.09 \\
\hline OM2 & 19.18 & 17.48 & 13.66 & 12.48 & 8.77 \\
\hline Total time & 26.71 & 24.12 & 18.65 & 16.67 & 11.84 \\
\hline Total CTI & 9.08 & 8.93 & 8.56 & 8.29 & 8.165 \\
\hline
\end{tabular}

Table 10. The results of 30 trials test

\begin{tabular}{l|c|c}
\hline Operating mode & OM1 & OM2 \\
\hline Best & 3.14 & 8.701 \\
\hline Mean & 3.14 & 8.847 \\
\hline Worst & 3.14 & 8.984 \\
\hline STD & $10^{-8}$ & 0.111 \\
\hline Range & $10^{-8}$ & 0.283 \\
\hline
\end{tabular}

time of the OCR protection for the IEC benchmark microgrid has decrease over time, by enhancing the constraint and demonstrating the ability of the proposed technique on the OCR's parameters setting.

In comparison to existing works, the proposed technique is successfully reduced the total operating time and total CTI of the OCR as shown in Table 9.

The proposed algorithm has been tested with 30 trials to verify the optimal results. Table 10 shows the best, mean, worst, range, and standard deviation 


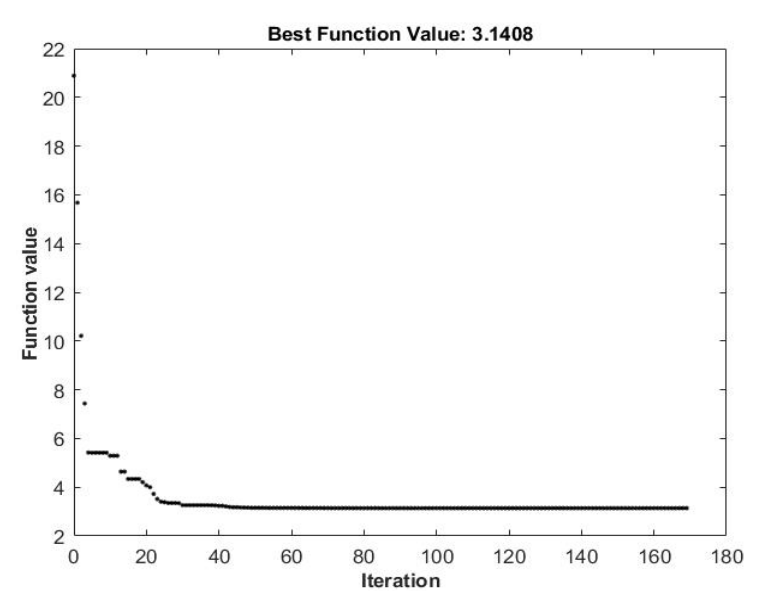

(a)

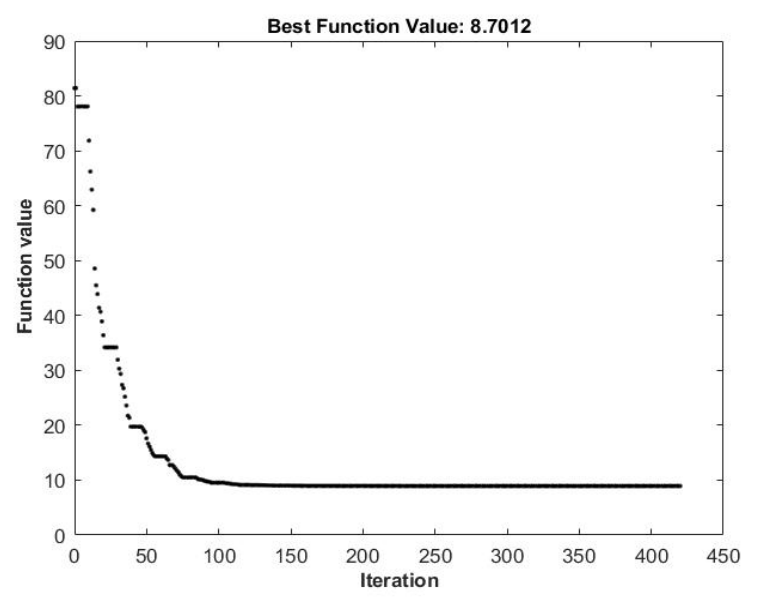

(b)

Figure. 5 Convergences plots of the proposed method: (a) OM1 and (b) OM2

(STD) of the optimal results. From Table 10, it is clear that the biggest advantage of the proposed technique is that it provides the optimal results with significantly low STD. Hence, the proposed hybrid PSO-MILP technique is suitable for finding the global minimum objective function value of the overcurrent relay coordination. The convergence plot of the proposed method is shown in Fig. 5.

\section{Conclusion}

The PSO-MILP technique is used, in this paper, for obtaining the optimal setting parameters of OCR coordination, which are TMS and CS. The total operating time of the relay in the system is minimized by maintaining the reliability of the system through the coordination constraint. As a result, the proposed technique provides the results with multiple curve types instead of single curve types. When compared to previous researches, the proposed technique can absolutely decrease the total operating time of the OCR by around 34 percent for OM1 and around 44 percent for OM2. Therefore, it can be concluded that the proposed method is suitable for the microgrid protection strategy. To demonstrate the usefulness of the proposed technique, the larger system, and other $C S$ types can be considered in further work.

\section{Conflicts of interest}

The authors declare no conflict of interest.

\section{Author contributions}

Conceptualization, methodology, validation, formal analysis, and investigation, C. Plongkrathok and K. Chayakulkheeree; writing original draft preparation, visualization, C. Plongkrathok; writingreview and editing, supervision, $\mathrm{K}$. Chayakulkheeree.

\section{References}

[1] V. A. Papaspiliotopoulos, G. N. Korres, V. A. Kleftakis, and N. D. Hatziargyriou, "HardwareIn-the-Loop Design and Optimal Setting of Adaptive Protection Schemes for Distribution Systems With Distributed Generation", IEEE Transactions on Power Delivery, Vol. 32, No. 1, pp. 393-400, 2017.

[2] B. Chattopadhyay, M. S. Sachdev, and T. S. Sidhu, "An on-line relay coordination algorithm for adaptive protection using linear programming technique", IEEE Transactions on Power Delivery, Vol. 11, No. 1, pp. 165-173, 1996.

[3] P. P. Bedekar, S. R. Bhide, and V. S. Kale, "Optimum Coordination of Overcurrent Relays in Distribution System Using Dual Simplex Method", In: Proc. of 2009 Second International Conference on Emerging Trends in Engineering \& Technology, pp. 555-559, 2009.

[4] A. Gupta, O. V. G. Swathika, and S. Hemamalini, "Optimum Coordination of Overcurrent Relays in Distribution Systems Using Big-M and Dual Simplex Methods", In: Proc. of 2015 International Conference on Computational Intelligence and Communication Networks (CICN), pp. 1540$1543,2015$.

[5] A. M. S. Deepak, S. Madhu, M. V. G. Raju, and O. V. G. Swathika, "Optimum coordination of overcurrent relays in distribution systems using big-m and revised simplex methods", In: Proc. of 2017 International Conference on Computing Methodologies and Communication (ICCMC), pp. 613-616, 2017. 
[6] A. M. Ibrahim, W. E. Khattam, M. E. Mesallamy, and H. A. Talaat, "Adaptive protection coordination scheme for distribution network with distributed generation using ABC", Journal of Electrical Systems and Information Technology, Vol. 3, Issue 2, pp. 320-332, 2016.

[7] A. Tjahjono, D. Anggriawan, A. Faizin, A. Priyadi, M. Pujiantara, T. Taufik, and M. Purnomo, "Adaptive modified firefly algorithm for optimal coordination of overcurrent relays", IET Generation Transmission \& Distribution, Vol. 11, Issue 10, pp. 2575-2585, 2017.

[8] T. Amraee, "Coordination of Directional Overcurrent Relays Using Seeker Algorithm", IEEE Transactions on Power Delivery, Vol. 27, No. 3, pp. 1415-1422, 2012.

[9] A. Srivastava, J. M. Tripathi, R. Krishan, and S. K. Parida, "Optimal Coordination of Overcurrent Relays Using Gravitational Search Algorithm With DG Penetration", IEEE Transactions on Industry Applications, Vol. 54, No. 2, pp. 1155-1165, 2018.

[10] P. P. Bedekar and S. R. Bhide, "Optimum Coordination of Directional Overcurrent Relays Using the Hybrid GA-NLP Approach", IEEE Transactions on Power Delivery, Vol. 26, No. 1, pp. 109-119, 2011.

[11] D. Saha, A. Datta, and P. Das, "Optimal coordination of directional overcurrent relays in power systems using Symbiotic Organism Search Optimisation technique", IET Generation Transmission \& Distribution, Vol. 10, Issue 11, pp. 2681-2688, 2015.

[12] A. S. Noghabi, J. Sadeh, and H. R. Mashhadi, "Considering Different Network Topologies in Optimal Overcurrent Relay Coordination Using a Hybrid GA", IEEE Transactions on Power Delivery, Vol. 24, No. 4, pp. 1857-1863, 2009.

[13] T. Khurshaid, A. Wadood, C. Kim, S. G. Farkoush, K. H. Kharal, and S. Rhee, "A Protective Optimal Coordination Scheme for Directional Overcurrent Relays Using Modified Seeker Algorithm", In: Proc. of 2018 International Conference on Computing, Power and Communication Technologies (GUCON), pp. 535-539, 2018.

[14] T. Khurshaid, A. Wadood, S. G. Farkoush, J. $\mathrm{Yu}, \mathrm{C}$. Kim, and S. Rhee, "An Improved Optimal Solution for the Directional Overcurrent Relays Coordination Using Hybridized Whale Optimization Algorithm in Complex Power Systems", IEEE Access, Vol. 7, pp. 90418-90435, 2019.
[15] A. Y. Hatata and A. Lafi, "Ant Lion Optimizer for Optimal Coordination of DOC Relays in Distribution Systems Containing DGs", IEEE Access, Vol. 6, pp. 72241-72252, 2018.

[16] S. M. Saad, N. E. Naily, and F. A. Mohamed, "A new constraint considering maximum PSM of industrial over-current relays to enhance the performance of the optimization techniques for microgrid protection schemes", Sustainable Cities and Society, Vol. 44, pp. 445-457, 2019.

[17] N. E. Naily, S. M. Saad, T. Hussein, F. A. Mohamed, "A novel constraint and nonstandard characteristics for optimal overcurrent relays coordination to enhance microgrid protection scheme", IET Generation Transmission \& Distribution, Vol. 13, Issue 6, pp. 780-793, 2019.

[18] S. D. S. Zuluaga, J. M. L. Lezama, and N. M. Galeano, "Optimal Coordination of Overcurrent Relays in Microgrids Considering a Non-Standard Characteristic", Energies, Vol. 13, Issue 4, 2020.

[19] M. N. Alam, "Overcurrent protection of AC microgrids using mixed characteristic curves of relays", Computers \& Electrical Engineering, Vol. 74, pp. 74-88, 2019.

[20] S. D. S. Zuluaga, J. M. L. Lezama, and N. M. Galeano, "An Approach for Optimal Coordination of Over-Current Relays in Microgrids with Distributed Generation", Electronics, Vol. 9, Issue 10, 2020.

[21] J. Kennedy and R. Eberhart, "Particle swarm optimization", In: Proc. of ICNN'95 International Conference on Neural Networks, Vol. 4, pp. 1942-1948, 1995.

[22] S. Kar, "A comprehensive protection scheme for micro-grid using fuzzy rule base approach", Energy Systems, Vol. 8, pp. 449-464, 2017.

[23] S. Kar, S. R. Samantaray, and M. D. Zadeh, "Data-Mining Model Based Intelligent Differential Microgrid Protection Scheme", IEEE Systems Journal, Vol. 11, No. 2, pp. 1161-1169, 2017. 